\title{
The molecular phylogenetic signature of Bali cattle revealed by maternal and paternal markers
}

\author{
S. M. F. Syed-Shabthar - M. K. A. Rosli • N. A. A. Mohd-Zin • \\ S. M. N. Romaino - Z. A. Fazly-Ann • M. C. Mahani • O. Abas-Mazni • \\ R. Zainuddin $\cdot$ S. Yaakop $\cdot$ B. M. Md-Zain
}

Received: 2 August 2012/Accepted: 30 April 2013/Published online: 20 May 2013

(C) Springer Science+Business Media Dordrecht 2013

\begin{abstract}
Bali cattle is a domestic cattle breed that can be found in Malaysia. It is a domestic cattle that was purely derived from a domestication event in Banteng (Bos javanicus) around 3,500 BC in Indonesia. This research was conducted to portray the phylogenetic relationships of the Bali cattle with other cattle species in Malaysia based on maternal and paternal lineage. We analyzed the cytochrome c oxidase I (COI) mitochondrial gene and SRY of $\mathrm{Y}$ chromosome obtained from five species of the Bos genus (B. javanicus, Bos gaurus, Bos indicus, Bos taurus, and Bos grunniens). The water buffalo (Bubalus bubalis) was used as an outgroup. The phylogenetic relationships were observed by employing several algorithms: NeighborJoining (PAUP version 4.0), Maximum parsimony (PAUP version 4.0) and Bayesian inference (MrBayes 3.1). Results from the maternal data showed that the Bali cattle formed a monophyletic clade, and together with the B. gaurus clade formed a wild cattle clade. Results were supported by high
\end{abstract}

S. M. F. Syed-Shabthar - M. K. A. Rosli .

N. A. A. Mohd-Zin · M. C. Mahani - S. Yaakop

B. M. Md-Zain ( $\square)$

School of Environmental and Natural Resource Sciences, Faculty of Science and Technology, Universiti Kebangsaan Malaysia, 43600 Bangi, Selangor, Malaysia

e-mail: abgbadd@ukm.my; abgbadd1966@yahoo.com

S. M. N. Romaino · Z. A. Fazly-Ann ·

O. Abas-Mazni

Agro-Biotechnology Institute, Malaysia (ABI),

43400 Serdang, Selangor, Malaysia

R. Zainuddin

Molecular Ecology Laboratory, Faculty of Resource Science and Technology, Universiti Malaysia Sarawak,

94300 Kota Samarahan, Sarawak, Malaysia bootstrap and posterior probability values together with genetic distance data. For the paternal lineage, the sequence variation is low (with parsimony informative characters: 2/660) resulting an unresolved Neighbor-Joining tree. However, Bali cattle and other domestic cattle appear in two monophyletic clades distinct from yak, gaur and selembu. This study expresses the potential of the COI gene in portraying the phylogenetic relationships between several Bos species which is important for conservation efforts especially in decision making since cattle is highly bred and hybrid breeds are often formed. Genetic conservation for this high quality beef cattle breed is important by maintaining its genetic characters to prevent extinction or even decreased the genetic quality.

Keywords Bali cattle - Bos javanicus · Gaur · Cytochrome $\cdot \mathrm{C}$ oxidase I $\cdot$ SRY gene

\section{Introduction}

Classified under the Bos genus, cattle are divided into four species which are Bos gaurus (gaur), Bos javanicus (Banteng), Bos indicus (Zebu cattle) and Bos taurus (Taurine cattle) [1]. According to Porter [2], there is a population of about 1.3 billion cattle globally and there are more than a thousand breeds of cattle worldwide. Among these cattle, both gaur and Banteng are wild cattle. For domestic cattle breeds there are two groups, the Zebu and the Taurine cattle [3-5]. Taurine cattle are humpless while Zebu cattle are humped and they are believed to have originated from aurochs, Bos primigenius through a domestication event that occurred 8,000-10,000 years before present (B.P.) $[4,6]$. Domestic cattle are presently among the most developed livestock achieved through domestication and 